\title{
Response Surface Methodology for the Optimization of Chlorpyrifos-Degrading Conditions by Pseudomonas stutzeri ZH-1
}

\author{
Feng He${ }^{1}$, Mimi Zhang2, Lihong Zhang1, Qingping $\mathrm{Hu}^{{ }^{*}}$ \\ ${ }^{1}$ College of Life Science, Shanxi Normal University, Linfen, China \\ ${ }^{2}$ Modern College of Humanities Sciences, Shanxi Normal University, Linfen, China \\ Email: *hqp72@163.com
}

How to cite this paper: He, F., Zhang, M.M., Zhang, L.H. and Hu, Q.P. (2018) Response Surface Methodology for the Optimization of Chlorpyrifos-Degrading Conditions by Pseudomonas stutzeri ZH-1. Open Access Library Journal, 5: e4405. https://doi.org/10.4236/oalib.1104405

Received: February 5, 2018

Accepted: March 12, 2018

Published: March 15, 2018

Copyright $\odot 2018$ by authors and Open Access Library Inc.

This work is licensed under the Creative Commons Attribution International License (CC BY 4.0).

http://creativecommons.org/licenses/by/4.0/

\section{(c) (i) Open Access}

\begin{abstract}
The removal of pesticides in the environment mainly depends on natural degradation, especially on microbial degradation. Biodegradation has many advantages, such as complete degradation, no secondary pollution, quick effect and wide spectrum. Based on the single-factor experiments and Box-Benhnken design, the effect of four factors on the degradation of chlorpyrifos by $P$. stutzeri $\mathrm{ZH}-1$ was investigated. The four factors, including temperature $\left({ }^{\circ} \mathrm{C}\right)$, oscillator speed (rpm), inoculum concentration (\%) and $\mathrm{pH}$, and their interactions on the degradation of chlorpyrifos were studied through the use of response surface analysis. The optimal conditions of chlorpyrifos-degrading were as follows: Temperature $36.7^{\circ} \mathrm{C}$, oscillator speed $130.00 \mathrm{rpm}$, inoculum concentration $7 \%, \mathrm{pH} 7$. Under these conditions, the degradation rate of chlorpyrifos was $96.48 \%$. Moreover, P. stutzeri $\mathrm{ZH}-1$ could be used efficiently for remediation of contaminated soils.
\end{abstract}

\section{Subject Areas}

Microbiology

\section{Keywords}

Response Surface Methodology, Chlorpyrifos-Degrading, Pseudomonas Stutzeri $\mathrm{ZH}-1$

\section{Introduction}

In order to meet the growing demand for food, farmers grow high-yielding crop varieties all over the country in China. However, these high-yielding crop varie- 
ties are highly susceptible to various pests and diseases; thus, to protect their crops from pests and to improve their crop yields and quality of their products, farmers use pesticides [1]. Because of the characteristics of high efficiency, low cost, easy operation in the prevention and control of pests, organophosphorus pesticide (OPPs) is widely used for agricultural production at home and abroad. Whereas almost $80 \%$ of OPPS remains in farmland, and these soluble or insoluble compounds cause serious environmental pollution. OPPs poisons the stomach of the human and inhibits enzyme activity by binding the enzyme acetylcholinesterase (AChE) through phosphorylation, resulting in the death of the human body [2]. Therefore, how to effectively eliminate of organophosphorus pesticide residues in the environment pollution has become a severe problem to be solved urgently.

Chlorpyrifos [O,O-diethyl O-(3,5,6-trichloro-2-pyridyl) phosphorothioate] is used worldwide as an agricultural insecticide [3]. Its solubility is extremely low in water but is relatively high in most organic solvents. Its environmental fate has been extensively studied, and its half-life in soil varies from 10 to 120 days, resulting in 3,5,6-trichloro-2-pyridinol (TCP) as the major degradation product [4]. The extensive use of chlorpyrifos has led to widespread environmental pollution, resulting in serious damage to non-target species. The control of chlorpyrifos pollutants is of great importance because they are toxic and recalcitrant.

Bioremediation is defined as the process that organic wastes are biologically degraded to an innocuous state or to the levels below concentration limits established by regulatory authorities under controlled conditions. Bioremediation, which involves the use of microbes to detoxify and degrade pollutants, has received increased attention as an effective biotechnological approach to clean up polluted environments [5]. At present, the use of chlorpyrifos-degrading bacteria for bioremediation of chlorpyrifos-contaminated sites has been proved to be the most potential clean-up method. Mallick et al. found the Arthrobacter sp. in the soil, which can degrade the chlorpyrifos in the inorganic medium, and the degradation rate of the $10 \mathrm{ug} / \mathrm{mL}$ chlorpyrifos was $100 \%$ in $48 \mathrm{~h} \mathrm{[6]}$. Singh et al. isolated Enterobacter sp. B-14, one bacterial, which is capable of degrading chlorpyrifos in liquid media and soil [7]. Besides, a bacterial strain Pseudomonas stutzeri $Y C$ - $Y H 1$, that degraded $100 \%$ of chlorpyrifos (100 $\mathrm{mg} / \mathrm{L}$ ) initially added within 4 days, was isolated from sludge by Shi Yanhua [8].

Holden, Firestone and Vidali suggested that the success of microbial degradation depends on a number of factors, like $\mathrm{pH}$, organic matter, moisture, temperature and nutrient status [9] [10]. The aim of the present work was to optimize the conditions of the Pseudomonas stutzeri $\mathrm{ZH}-1$ (P. stutzeri $\mathrm{ZH}-1$ ) for the degradation of chlorpyrifos by the response surface method (RSM). It is of great significance in the development of more successful strategies aiming at exploiting more beneficial microbe resources for degradation of chlorpyrifos. 


\section{Materials and Methods}

\subsection{Chemicals}

Chlorpyrifos (in the form of Hubei Sanonda Co. Ltd., China) was purchased from a local pesticide supplier (Linfen, China). High-performance liquid chromatography (HPLC) grade methanol was purchased from the Tianjin Guangfu Chemical Reagent Co., Ltd, China. All other reagents used in this study were analytical reagent grade [11].

\subsection{Microorganism and Inoculum Preparation}

A strain of $P$. stutzeri $\mathrm{ZH}-1$ was separated from the sludge of the Fenhe River in Shanxi province of China. Based on the morphological, biochemical, the Bergey's Manual of Determinative Bacterriology and 16S-rDNA gene sequence analysis, strain $\mathrm{ZH}-1$ was recognized as a strain of $P$. stutzeri and was thereafter named $P$. stutzeri ZH-1. The NCBI accession number is DQ513513. It was cultivated on standard nutrient agar (NA) medium periodically at $37^{\circ} \mathrm{C}$ for $24 \mathrm{~h}$. Fresh slant cultures were used in every batch for inoculation. Nutrient broth (NB) was inoculated with a $24 \mathrm{~h}$ old culture and grow at $37^{\circ} \mathrm{C}$ on a shaker at $140 \mathrm{rpm}$ for $12 \mathrm{~h}$.

\subsection{Media for Batch Reactor Studies}

The composition of the Mongina medium used for chlorpyrifos-degrading was as follows: glucose $=10 \mathrm{~g} / \mathrm{L}, \mathrm{NH}_{4} \mathrm{Cl}=0.5 \mathrm{~g} / \mathrm{L}, \mathrm{NaCl}=0.3 \mathrm{~g} / \mathrm{L}, \mathrm{KCl}=0.3 \mathrm{~g} / \mathrm{L}$, $\mathrm{MgSO}_{4}=0.03 \mathrm{~g} / \mathrm{L}, \mathrm{FeSO}_{4}=0.03 \mathrm{~g} / \mathrm{L}, \mathrm{MnSO}_{4}=0.03 \mathrm{~g} / \mathrm{L}, \mathrm{CaCl}_{2}=5 \mathrm{~g} / \mathrm{L}[12]$. Tranfer $2.5 \mathrm{~g}$ of chlorpyrifos (40\%) to a 250 - $\mathrm{ml}$ volumetric flsk, dilute with the chromatography grade methanol to volume, and mix. The concentration of the chlorpyrfos was $1 \times 10^{4} \mathrm{mg} / \mathrm{L}$, which is placed in a brown glass bottle. Then $1 \mathrm{ml}$ of the chlorpyrifos was added to the medium of $50 \mathrm{ml}$, and the concentration of chlorpyrifos in the culture medium was $200 \mathrm{mg} / \mathrm{L}$.

\subsection{Single-Factor Experiments}

For the investigation of the effect of the initial $\mathrm{pH}$ value on chlorpyrifos-degrading, the $\mathrm{pH}$ value of the medium was adjusted to3.0 4.0, 5.0, 6.0, 7.0, 8.0, 9.0, 10.0, 11.0 or 12.0. For the sake of investigating the effect of the temperature on chlorpyrifosdegrading, the culture was incubated at $20^{\circ} \mathrm{C}, 25^{\circ} \mathrm{C}, 30^{\circ} \mathrm{C}, 35^{\circ} \mathrm{C}, 40^{\circ} \mathrm{C}$ or $45^{\circ} \mathrm{C}$. In order to study the effect of the inoculum concentration (v/v)on chlorpyrifosdegrading, cells were inoculated at into cultures at $1 \%, 2 \%, 3 \%, 4 \%, 5 \%, 6 \%, 7 \%$, $8 \%, 9 \%$ or $10 \%$. To explore the effect of the oscillator speed on chlorpyrifosdegrading, the oscillator speed was controlled at $0,40,80,120,160$ or $200 \mathrm{rpm}$. For all experiments, cells were inoculated at $2 \%(\mathrm{v} / \mathrm{v})$ into cultures of $\mathrm{pH} 7.0$, then they were incubated at $37^{\circ} \mathrm{C}$ on a shaker at $140 \mathrm{rpm}$ for 5 days unless otherwise stated [11].

\subsection{Optimization Experiments}

RSM was chosen to show the statistical significance of the effects $\mathrm{pH}$, tempera- 
ture, inoculum concentration and oscillator speed on the degradation of chlorpyrifos by $P$. stutzeri $\mathrm{ZH}-1$. The RSM experiments were designed by using the Design-Expert 7.1.3. Calculations were done at $95 \%$ of confidence level. In order to optimize the incubation conditions and investigate effects of above independent variables on the degradation of chlorpyrifos, a central-composite rotary design with the variables at three levels was used in the experiments.

\subsection{Analysis of Chlorpyrifos}

HPLC was used for detection of concentrations of insecticide. To extract chlorpyrifos from Mongina medium, $5 \mathrm{ml}$ of liquid samples were centrifuged at 6000 $\mathrm{rpm}$ for $20 \mathrm{~min}$ at $4^{\circ} \mathrm{C}$. Chlorpyrifos in the supernatant fluid was extracted with an equal volume of dichloromethane, then oscillated for 10 minutes by the use of ultrasonic waves. The extract was dried over anhydrous $\mathrm{Na}_{2} \mathrm{SO}_{4}$ and dry using Termovap Sample Concentrator at room temperature. Residual was dissolved in an equal volume of methanol, then filter the membrane with $0.22 \mathrm{um}$. All samples were analyzed by HPLC (1260LC, Rheodyne 7750i manual injector and Variable Wavelength uv Detector; Agilent Technology Co.). Zorbax Eclipse XDB-C18 stationary phase was used in the separation column $(4.6 \mathrm{~mm}$ internal diameter and $25 \mathrm{~cm}$ length). The mobile phase was methanol:water $(80: 20, \mathrm{v} / \mathrm{v})$, and the flow rate was $1.0 \mathrm{ml} / \mathrm{min}$. Chlorpyrifos was detected at uv wavelength of $290 \mathrm{~nm}$.

\subsection{Calculation of Degradation Rate}

Based on the peak area of control group and test group respectively to calculate chlorpyrifos concentration in the sample through the regression equation of reference standard curve, the corresponding chlorpyrifos degradation rate can be obtained.

$$
\text { Degradation rate }=\left(1-C_{1} / C_{0}\right) \times 100 \% \text {. }
$$

where, $C_{1}(\mathrm{mg} / \mathrm{L})$ was the residual concentration of the test group after the degradation of bacteria, while $C_{0}(\mathrm{mg} / \mathrm{L})$ was the residual concentration of chlorpyrifos in the control group.

\section{Results and Discussion}

\subsection{Standard Curve of Chlorpyrifos}

Figure 1 showed HPLC can detect the concentration of chlorpyrifos, the standard curve of the concentration of chlorpyrifos was drawn. When chlorpyrifos concentration range of $5-200 \mathrm{mg} / \mathrm{L}$, the standard curve equation is: $\mathrm{y}=5.3745 \mathrm{x}$ +8.9361 . The correlation coefficient $\mathrm{R}^{2}=0.9987$. The standard curve equation shows that the correlation between the measured concentration of chlorpyrifos and peak area can be used to calculate chlorpyrifos concentration.

\subsection{Effects of $\mathrm{pH}$ on the Degradation of Chlorpyrifos by $P$. stutzeri $\mathrm{ZH}-1$}

In previous studies, the degradation rate of chlorpyrifos is strongly related to soil 
$\mathrm{pH}$, and the degradation is microbial degradation and not due to abiotic hydrolysis [4]. The changes of $\mathrm{pH}$ value have a significant impact on cell growth and chlorpyrifos-degrading. When the $\mathrm{pH}$ value ranges from 1 to 7 , the biomass increase gradually. While if the $\mathrm{pH}$ value changes from 7 to 12 , the biomass decrease gradually. That is because the alkaline environment is not suitable for the growth of the bacteria. Suitable $\mathrm{pH}$ value can increase the reaction activity, and accelerate the utilization of chlorpyrifos as well as increase degradation rate of chlorpyrifos. In order to achieve the maximum degradation of chlorpyrifos, the fermentation optimum of $\mathrm{pH}$ gradient ranges from 3 to 12. Figure 2 showed that the maximum degradation rate of chlorpyrifos was obtained in $\mathrm{pH} 7$ media, and the degradation rate reached $92.90 \%$.

\subsection{Effects of Temperature on the Degradation of Chlorpyrifos by P. stutzeri $\mathrm{ZH}-1$}

In general, pesticide degradation in soil can be influenced by both biotic and

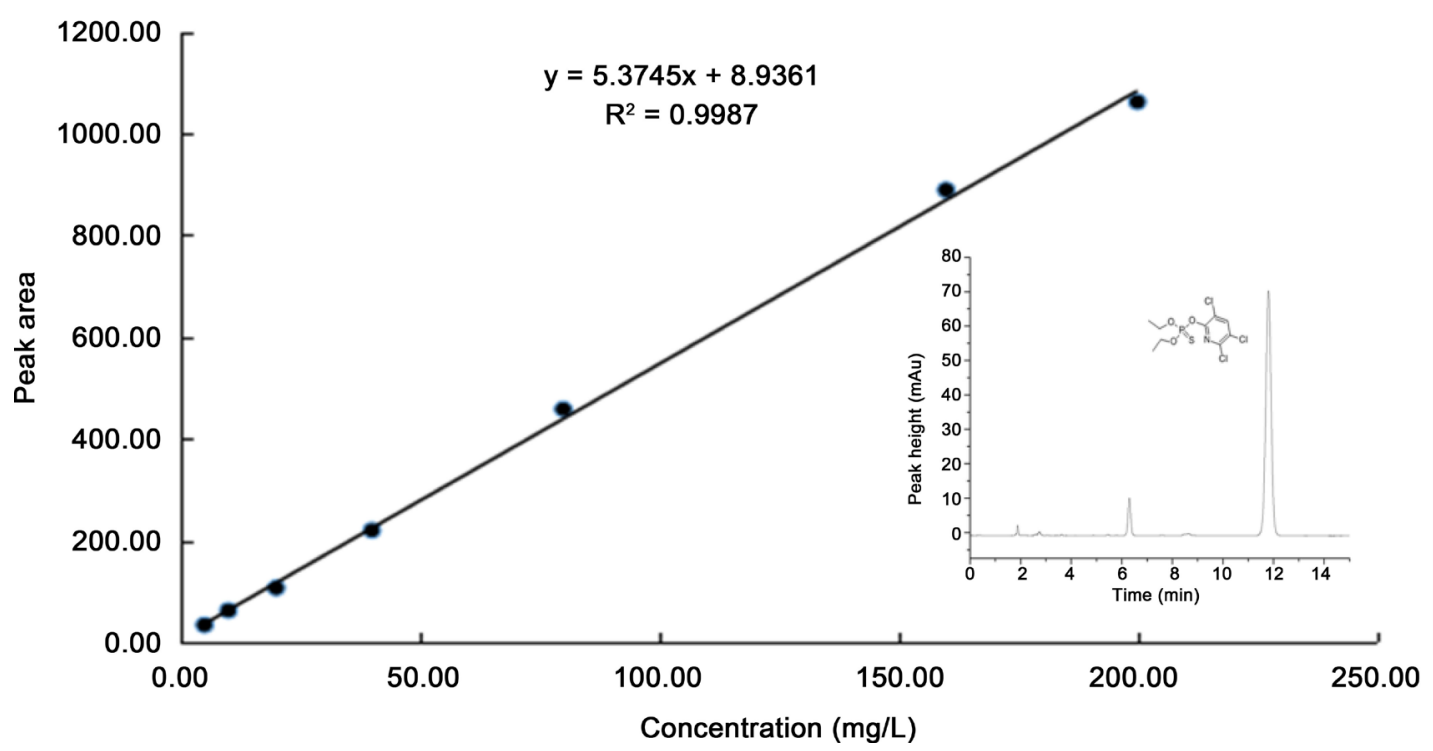

Figure 1. Standard curve of chlorpyrifos.

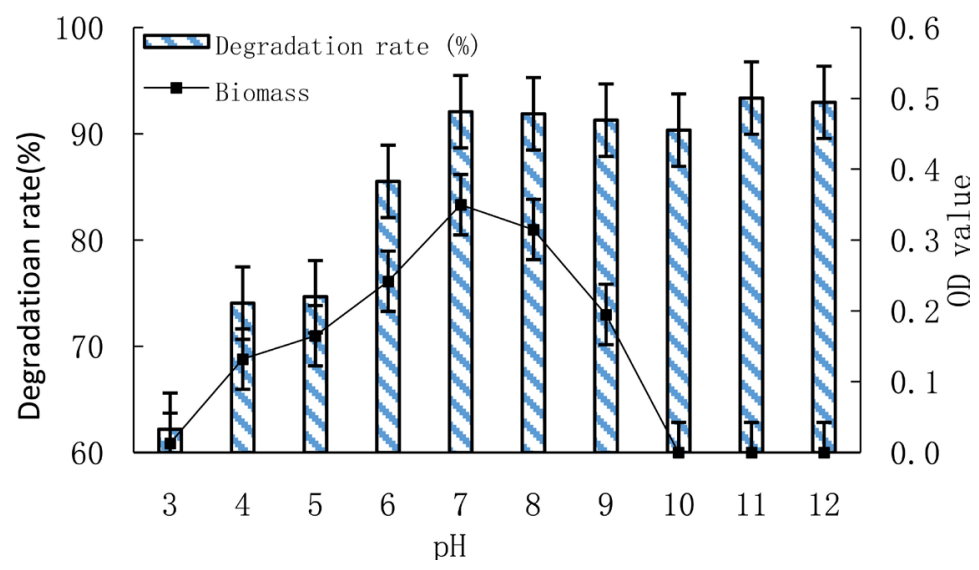

Figure 2. Effect of $\mathrm{pH}$ on chlorpyrifos-degrading rate. 
abiotic factors, which are linked and supplemented in series with each other in a micro environment. Environmental conditions play an important role in the survival and proliferation of microorganisms as well as the effect on chemical stability [13]. In order to achieve the maximum degradation of chlorpyrifos, the fermentation temperature varies from $20^{\circ} \mathrm{C}$ to $45^{\circ} \mathrm{C}$. Figure 3 showed that when the temperature was controlled at $20^{\circ} \mathrm{C}-35^{\circ} \mathrm{C}$ for 5 days, biomass increased with the temperature. The degradation rate of chlorpyrifos increased too as the increase of biomass. However, when the fermentation temperature exceeded $40^{\circ} \mathrm{C}$, degradation rate of chlorpyrifos has been significantly reduced. Lower fermentation temperature makes the growth of the bacteria be slow, thus to affect the degradation of chlorpyrifos. On the other hand, higher temperature inhibits the growth of bacteria and the degradation of chlorpyrifos. As a result, it is well proved that the optimal temperature was $35^{\circ} \mathrm{C}$.

\subsection{Effects of Inoculum Concentration on the Degradation of Chlorpyrifos by $P$. stutzeri ZH-1}

The inoculum age and density markedly influence the productivity and economics of bioprocesses [14]. Some literature reports demonstrated that appropriate inoculum concentration can improve the degradation of pesticide. The smaller inoculum concentration has lower utilization of chlorpyrifos. When the inoculum concentration was too high, a lot of cells grow and metabolites accumulate, which led to a decline in the degradation of chlorpyrifos. Figure 4 showed that the biomass increased when the inoculum concentration increased from $1 \%$ to $6 \%$. at the same time, degradation rate of chlorpyrifos increased, too. But there was a steep decrease degradation rate of chlorpyrifos once it was above $8 \%$. Thus, the optimal inoculum concentration was $6 \%$.

\subsection{Effects of Oscillator Speed on the Degradation of Chlorpyrifos by $P$, stutzeri $\mathrm{ZH}-1$}

P. stutzeri $\mathrm{ZH}-1$ is a facultative aerobic bacterium, the dissolved oxygen content determines the growth of the cells, what determines the degradation of chlorpyrifos.

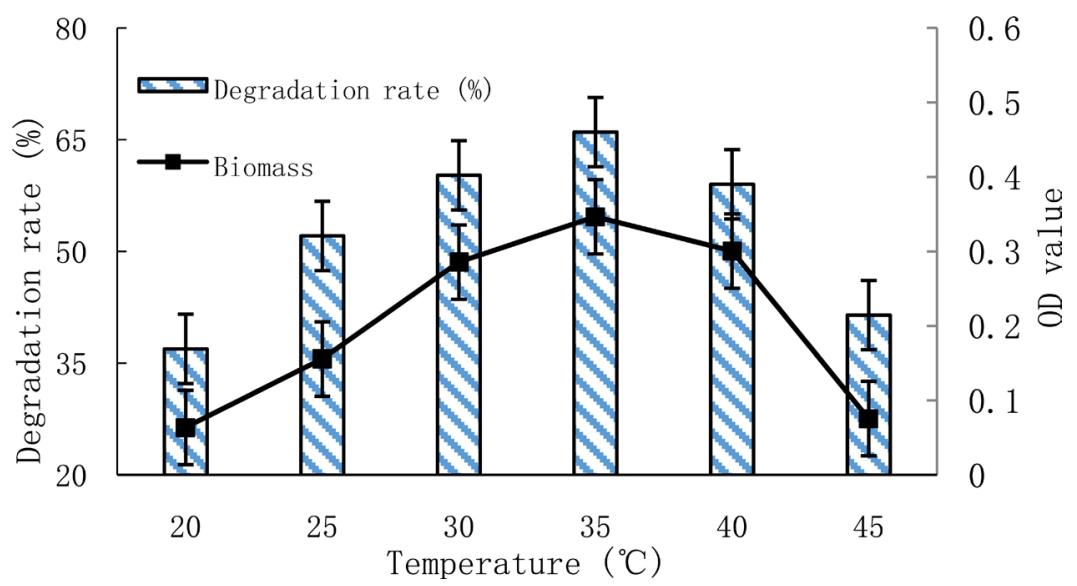

Figure 3. Effect of temperature on chlorpyrifos-degrading rate. 


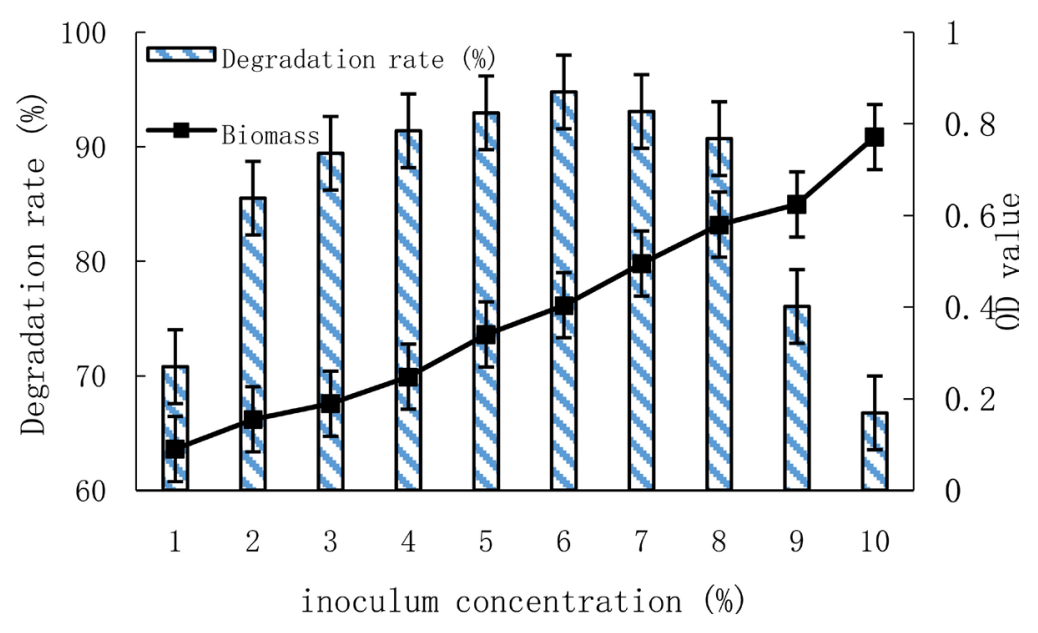

Figure 4. Effect of inoculum concentration on chlorpyrifos-degrading rate.

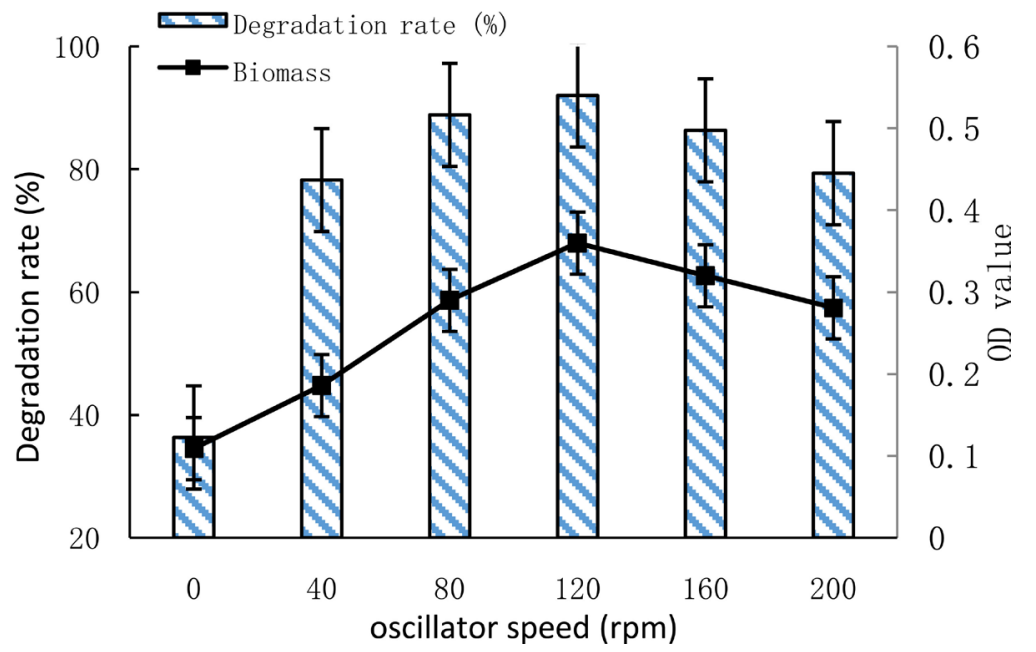

Figure 5. Effect of oscillator speed on chlorpyrifos-degrading rate.

Figure 5 showed that the oscillator speed was kept in 0 - $120 \mathrm{rpm}$ for 5 days, biomass increased with the oscillator speed, and the degradation rate of chlorpyrifos also increased. However, when the oscillator speed exceeded $160 \mathrm{rpm}$, degradation rate of chlorpyrifos has been significantly reduced. Lower oscillator speed induced the slower growth of the bacteria, thus to affect the degradation of chlorpyrifos.

\subsection{Optimization of Degradation Conditions $P$. stutzeri $\mathrm{ZH}-1$ via RSM}

Appropriate degradation conditions have an important significance on the degradation of chlorpyrifos. According to the Box-Benhnken central combination experiment principle, the selection the temperature, oscillator speed, inoculum concentration, and the $\mathrm{pH}$ value carried on four factors three levels were displayed in the response surface analysis experiments. Table 1 presents the design matrix for the experiment and the regression model proposed for response was given below: 
Table 1. Experimental design with real value a of chlorpyrifos-degrading rate.

\begin{tabular}{|c|c|c|c|c|c|}
\hline Run & $\begin{array}{c}\mathrm{X}_{1}\left({ }^{\circ} \mathrm{C}\right) \\
\text { temperature }\end{array}$ & $\begin{array}{c}\mathrm{X}_{2}(\mathrm{rpm}) \\
\text { Oscillator speed }\end{array}$ & $\begin{array}{c}\mathrm{X}_{2}(\%) \\
\text { inoculum concentration }\end{array}$ & $\begin{array}{c}\mathrm{X}_{4} \\
\mathrm{pH}\end{array}$ & $\begin{array}{c}\text { degradation } \\
\text { Rate }(\%)\end{array}$ \\
\hline 1 & $0(35)$ & $0(120)$ & $-1(4)$ & $-1(6)$ & 79.89 \\
\hline 2 & 0 & 0 & $1(8)$ & $1(8)$ & 85.70 \\
\hline 3 & 0 & $1(160)$ & $0(6)$ & -1 & 84.26 \\
\hline 4 & $1(40)$ & 1 & 0 & $0(7)$ & 89.89 \\
\hline 5 & 0 & $-1(80)$ & 0 & 1 & 83.31 \\
\hline 6 & 1 & 0 & 1 & 0 & 89.69 \\
\hline 7 & $-1(30)$ & 0 & -1 & 0 & 79.59 \\
\hline 8 & -1 & 0 & 0 & -1 & 81.99 \\
\hline 9 & 0 & 0 & 0 & 0 & 94.09 \\
\hline 10 & 0 & 0 & 0 & 0 & 95.80 \\
\hline 11 & -1 & -1 & 0 & 0 & 78.39 \\
\hline 12 & 0 & -1 & 0 & -1 & 81.78 \\
\hline 13 & 1 & 0 & -1 & 0 & 89.85 \\
\hline 14 & -1 & 1 & 0 & 0 & 75.56 \\
\hline 15 & 0 & 1 & 0 & 1 & 93.45 \\
\hline 16 & 0 & 1 & 1 & 0 & 90.53 \\
\hline 17 & 1 & 0 & 0 & 1 & 77.88 \\
\hline 18 & 0 & 0 & 0 & 0 & 95.39 \\
\hline 19 & 0 & 0 & 0 & 0 & 96.60 \\
\hline 20 & 1 & -1 & 0 & 0 & 82.09 \\
\hline 21 & 0 & -1 & 1 & 0 & 82.60 \\
\hline 22 & 0 & 0 & 1 & -1 & 92.51 \\
\hline 23 & 0 & 0 & -1 & 1 & 84.96 \\
\hline 24 & 0 & 0 & 0 & 0 & 95.72 \\
\hline 25 & -1 & 0 & 1 & 0 & 86.63 \\
\hline 26 & 1 & 0 & 0 & 1 & 88.15 \\
\hline 27 & 0 & 1 & -1 & 0 & 82.19 \\
\hline 28 & 1 & 0 & 0 & -1 & 89.03 \\
\hline 29 & 0 & -1 & -1 & 0 & 84.44 \\
\hline
\end{tabular}

$$
Y=\beta_{0}+\sum_{i=1}^{4} \beta_{i} X_{i}+\sum_{i=1}^{4} \beta_{i i} X_{i}^{2}+\sum_{i, j=1}^{4} \beta_{i j} X_{i} X_{j}+\varepsilon
$$

where $Y$ is predicted response, $X_{i} X_{j}$ are input variables which influence the response variable $Y ; \beta_{0}$ is the offset term; $\beta_{i}$ is the $i^{\text {th }}$ linear coefficient; $\beta_{i i}$ the $i^{\text {th }}$ quadratic coefficient and $\beta_{i j}$ is the $i j^{\text {th }}$ interaction coefficient. The term $\varepsilon$ allows for uncertainties or discrepancies between what the model predicts and what was 
actually measured and stands for residual [15]. The $\mathcal{\varepsilon}$ 's are not model parameters. While demonstrating the significant effects 3-dimensional fitted surfaces were drawn. A total of 29 experiments were carried out using the RSM method. The design expert software was performed for regression and graphical analysis of data obtained. The optimum levels of temperature, oscillator speed, inoculum concentration and $\mathrm{pH}$ were obtained by solving the regression equation and also analyzing the response surface contour plots.

Multiple regression analysis was used to analyse the data and thus a polynomial equation was derived from regression analysis as follows [15]:

$$
\begin{aligned}
Y= & -533.66400+17.34780 * X_{1}+0.036129 * X_{2}+26.03217 * X_{3}+63.95650 * X_{4} \\
& +0.01328 * X_{1} * X_{2}-0.18000 * X_{1} * X_{3}+0.16150 * X_{1} * X_{4} \\
& +0.031812 * X_{2} * X_{3}+0.047875 * X_{2} * X_{4}-1.48500 * X_{3} * X_{4} \\
& -0.25974 * X_{1}^{2}-4.07797 E-003 * X_{2}^{2}-100338 * X_{3}^{2}-4.72225 * X_{4}^{2}
\end{aligned}
$$

The adequacy of the model was checked using analysis of variance (ANOVA) which was tested using Fisher's statistical analysis and the results are showed in Table 2. The Model F-value of 11.87 implies the model is significant. There is only a $0.01 \%$ chance that a "Model F-Value" this large could occur due to noise. The $R^{2}$ value (multiple correlation coefficient) closer to 1 denotes better correlation between the observed and predicted values. In this case the value of R2 (0.922) indicates good correlation between the experimental and predicted values. The coefficient of variation (CV) indicates the degree of precision with which the experiments are compared. The lower reliability of the experiment is usually indicated by high value of CV. In the present case a low CV (2.76) denotes that the experiments performed are highly reliable.

The $\mathrm{P}$ values denotes the significance of the coefficients and also of importance in understanding the pattern of the mutual interactions between the variables. The regression analysis of the optimization study indicated that the model terms, $X_{1}, X_{3}, X_{1}^{2}, X_{2}^{2}, X_{3}^{2}$ and $X_{4}^{2}$ were very significant $(\mathrm{P}<0.01)$; $X_{2}, X_{1}{ }^{\star} X_{2}, X_{3}{ }^{\star} X_{4}$ were significant $(\mathrm{P}<0.05)$. The variable $X_{4}, X_{1}{ }^{*} X_{3}, X_{1}{ }^{\star} X_{4}$, $X_{2}{ }^{\star} X_{3}, X_{2}{ }^{*} X_{4}$ was not significant $(\mathrm{P}>0.05)$. However, Table 2 demonstrates the interactions between the variables $X_{1}{ }^{\star} X_{2}$ and $X_{3}{ }^{\star} X_{4}$ were significant, as was shown by the low $\mathrm{P}$-value. These results indicate that the relationship between temperature and oscillator speed, inoculum concentration and $\mathrm{pH}$ bear some direct effect on the degradation of chlorpyrifos.

Figure 6 showed the 3D graphs of response surface of chlorpyrifos' degradation rate. The slope of the response surface reflects the interaction of various factors and the relative significance of the degradation rate of chlorpyrifos. Taking Figure 6(a) as an example, the response value of the temperature change is greater than the response value of the oscillator speed variation, indicating that the change of temperature in the interaction is greater than the change of oscillator speed for the degradation of chlorpyrifos. By that analogy, the order of the main factors was as follows: temperature > inoculum concentration $>$ oscillator speed $>\mathrm{pH}$. 
Table 2. Model coefficient estimated by multiplies linear regression.

\begin{tabular}{|c|c|c|c|c|c|}
\hline \multirow{2}{*}{ Source } & \multirow{2}{*}{ Sum of squares } & \multirow{2}{*}{$\mathrm{df}$} & \multirow{2}{*}{ Mean square } & \multirow{2}{*}{ F value } & \multirow{2}{*}{$\begin{array}{c}\text { p-value } \\
\text { Prob }>F\end{array}$} \\
\hline & & & & & \\
\hline Model & 951.28 & 14 & 67.95 & 11.87 & $<0.0001$ \\
\hline$X_{1}$ & 197.32 & 1 & 197.32 & 34.46 & $<0.0001$ \\
\hline$X_{2}$ & 45.12 & 1 & 45.12 & 7.88 & 0.0140 \\
\hline$X_{3}$ & 59.59 & 1 & 59.59 & 10.41 & 0.0061 \\
\hline$X_{4}$ & 1.33 & 1 & 1.33 & 0.23 & 0.6377 \\
\hline$X_{1}{ }^{\star} X_{2}$ & 28.25 & 1 & 28.25 & 4.93 & 0.0433 \\
\hline$X_{1}{ }^{\star} X_{3}$ & 12.96 & 1 & 12.96 & 2.26 & 0.1547 \\
\hline$X_{1}{ }^{\star} X_{4}$ & 2.61 & 1 & 2.61 & 0.46 & 0.5107 \\
\hline$X_{2}{ }^{\star} X_{3}$ & 25.91 & 1 & 25.91 & 4.52 & 0.0517 \\
\hline$X_{2}{ }^{\star} X_{4}$ & 14.67 & 1 & 14.67 & 2.56 & 0.1318 \\
\hline$X_{3}{ }^{*} X_{4}$ & 35.28 & 1 & 35.28 & 6.16 & 0.0264 \\
\hline$X_{1}^{2}$ & 273.51 & 1 & 273.51 & 47.77 & $<0.0001$ \\
\hline$X_{2}^{2}$ & 276.15 & 1 & 276.15 & 48.23 & $<0.0001$ \\
\hline$X_{3}^{2}$ & 104.49 & 1 & 104.49 & 18.25 & 0.0008 \\
\hline$X_{4}^{2}$ & 144.65 & 1 & 144.65 & 25.26 & 0.0002 \\
\hline Residual & 80.16 & 14 & 5.73 & & \\
\hline Lack of Fit & 78.23 & 10 & 7.82 & 16.15 & 0.0082 \\
\hline Pure Error & 1.94 & 4 & 0.48 & & \\
\hline Cor Total & 1031.44 & 28 & & & \\
\hline
\end{tabular}

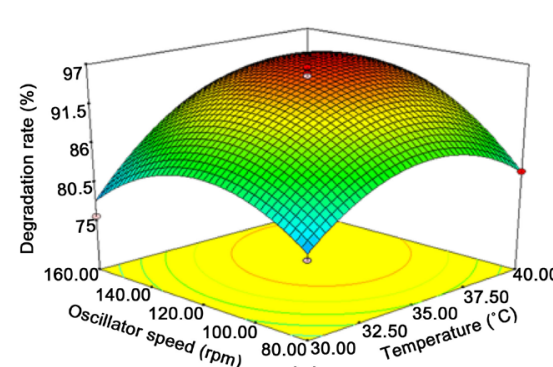

(a)

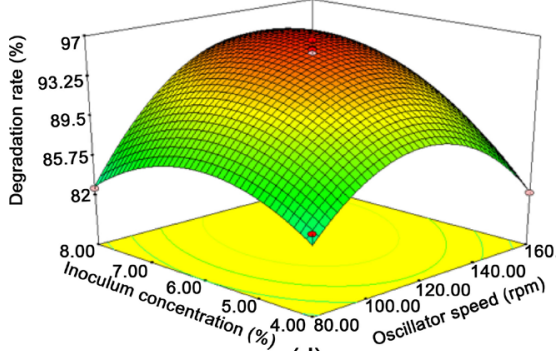

(d)

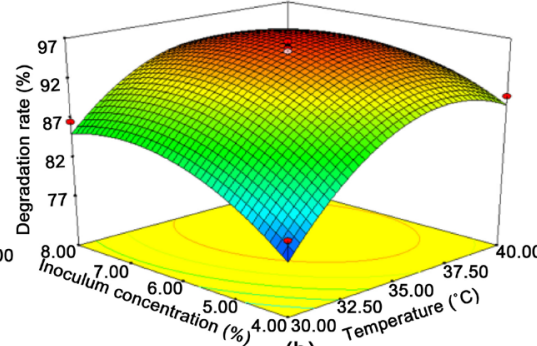

(b)

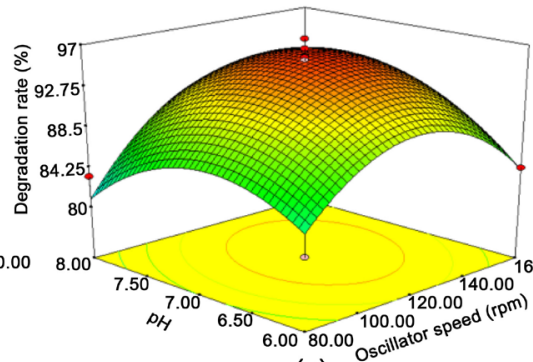

(e)

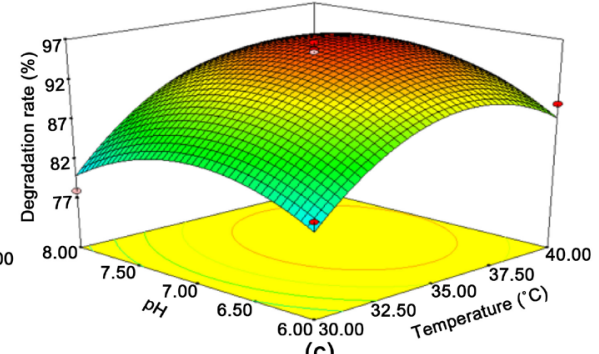

(c)

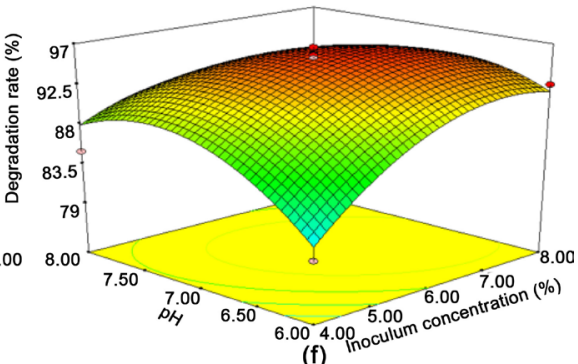

(f)

Figure 6. The 3D plots showing the effects of variables chlorpyrifos-degrading rate. (a) The interaction of temperature and oscillator speed. (b) The interaction of temperature and inoculum concentration. (c) The interaction of temperature and $\mathrm{pH}$. (d) The interaction of oscillator speed and inoculum concentration. (e) The interaction of oscillator speed and $\mathrm{pH}$. (f) The interaction of oinoculum concentration and $\mathrm{pH}$. 
The design expert presented the optimal conditions as following: temperature $36.66^{\circ} \mathrm{C}$, oscillator speed $131.00 \mathrm{rpm}$, inoculum concentration $6.65 \%$, $\mathrm{pH} 7.03$. Under these conditions, P. stutzeri $\mathrm{ZH}-1$ optimal degradation conditions of correction for temperature $36.7^{\circ} \mathrm{C}$, oscillator speed $130.00 \mathrm{rpm}$, inoculation concentration $7 \%$ and $\mathrm{pH} 7.0$, the degradation rate of chlorpyrifos actually measured is 96.48 . As the regression model to predict the theoretical value is up to 96.90 , the actual measured value is lower $0.43 \%$ than the theoretical value. Consequently, this result demonstrated the mathematical model can predict the relationship between the factors and degradation of chlorpyrifos effectively.

Success or failure of bioremediation depends on several factors, such as the competitive ability of the bioremedial agents, bioavailability of pollutants and abiotic factors such as soil moisture, $\mathrm{pH}$, and temperature. Successful removal of pesticides by the addition of bacteria has been previously reported for many compounds including, parathion, coumaphos, ethoprophos and atrazine [16]. Sikora et al. collected 21 samples of soil from the farmland where the effect of OPPs is not working, then he analyzed the activity of acid phosphatase, alkaine phosphatase, phosphodiesterase, triesterase phosphate and dehydrogenase. The results showed that these enzymes were involved in biodegradation of OPPs or the increase of biodegradation rates [17]. By studying the degradation and adsorption of TCP, Racke found that the degradation rate of TCP in soil was related to microbial components. As can be seen from the regression model, the microbial species are able to improve the degradation of TCP, and concluded that microbes work as the medium of TCP's mineralization [18]. Yang li et al isolated a strain of DSP3 from the soil of vegetable greenhouse, which could be the only carbon source and energy growth of chlorpyrifos. The degradation rate of the bacteria in the soil experiment of $20 \mathrm{~d}$ to the chlorpyrifos $(100 \mathrm{mg} / \mathrm{kg}$ ) was nearly 100\% [19]. The Rhodopesudomonas plaustris.HP-1, discovered by Zhang Deyong, can not only degrade methamidophos efficiently but also degrade 400 $\mathrm{mg} / \mathrm{L}$ chlorpyrifos after 7 days. Besides, the degradation achieved 50\% [20]. Xu et al. isolated a Paracoccus. Sp. TRP from the activated sludge, which has high degradation activity for chlorpyrifos [21]. Brajesh K. et al. demonstrated that the rapid degradation of chlorpyrifos was closely related to microorganism and $\mathrm{pH}$ in Australian soil [1]. Li Xiaohui et al. separated seven new bacterium capable of utilizing chlorpyrifos as the sole carbon. Among the seven new bacterium, they also identified six genera, which could enrich the resources of chlorpyrifos-degrading bacteria [3].

\section{Conclusions}

This work showed that the $P$. stutzeri ZH-1 had a high degradation of chlorpyrifos. In general, the degradation rate of chlorpyrifos increased with the increase of bacterial content. The optimal conditions of chlorpyrifos-degrading were as follows: Temperature $36.7^{\circ} \mathrm{C}$, oscillator speed $130.00 \mathrm{rpm}$, inoculum concentration $7 \%, \mathrm{pH}$ 7. The degradation rate of chlorpyrifos predicted was $96.60 \%$ by this 
model and the test value under optimal condition was $96.48 \%$.

It was investigated that the degradation capacity of $P$. stutzeri $\mathrm{ZH}-1$ was changeable under different environmental conditions and the environmental factors had great influence on degradation process. The acquiring of degradation bacteria's optimum degradation conditions are able to provide data support and reference for the application of this bacteria. In addition, this also develops one new resource for pesticide degradation bacteria.

\section{Acknowledgements}

This work was supported by grants from Student's Platform for Innovation and Entrepreneurship Training Program of Shanxi Province, China (2017574), and the Natural Science Foundation of Shanxi Normal University program (No. ZR1514).

\section{References}

[1] Sumon, K.A., Saha, S., Brink, P.J.V.D., Peeters, E.T.H.M., Bosma, R.H. and Rashid, H. (2017) Acute Toxicity of Chlorpyrifos to Embryo and Larvae of Banded Gourami Trichogaster fasciata. Journal of Environmental Science \& Health. Part. B Pesticides Food Contaminants \& Agricultural Wastes, 52, 92-98. https://doi.org/10.1080/03601234.2016.1239979

[2] Cycon', M., Wójcik, M. and Piotrowskaseget, Z. (2009) Biodegradation of the Organophosphorus Insecticide Diazinon by Serratia sp. and Pseudomonas sp. and Their Use in Bioremediation of Contaminated Soil. Chemosphere, 76, 494-501. https://doi.org/10.1016/j.chemosphere.2009.03.023

[3] Li, X., Jiang, J., Gu, L., Ali, S.W., He, J. and Li, S. (2008) Diversity of Chlorpyrifos-Degrading Bacteria Isolated from Chlorpyrifos-Contaminated Samples. International Biodeterioration \& Biodegradation, 62, 331-335. https://doi.org/10.1016/j.ibiod.2008.03.001

[4] Singh, B.K., Walker, A., Morgan, J.A. and Wright, D.J. (2003) Effects of Soil pH on the Biodegradation of Chlorpyrifos and Isolation of a Chlorpyrifos-Degrading Bacterium. Applied \& Environmental Microbiology, 69, 5198-206. https://doi.org/10.1128/AEM.69.9.5198-5206.2003

[5] Singh, B.K., Walker, A. and Wright, D.J. (2006) Bioremedial Potential of Fenamiphos and Chlorpyrifos Degrading Isolates: Influence of Different Environmental Conditions. Soil Biology \& Biochemistry, 38, 2682-2693. https://doi.org/10.1016/j.soilbio.2006.04.019

[6] Mallick, K., Bharati, K., Banerji, A., Shakil, N.A. and Sethunathan, N. (1999) Bacterial Degradation of Chlorpyrifos in Pure Cultures and in Soil. Bulletin of Environmental Contamination \& Toxicology, 62, 48-54.

https://doi.org/10.1007/s001289900840

[7] Singh, B.K., Walker, A., Morgan, J.A.W. and Wright, D.J. (2004) Biodegradation of chlorpyrifos by Enterobacter strain B-14 and Its Use in Bioremediation of Contaminated Soils. Applied \& Environmental Microbiology, 70, 4855-4863. https://doi.org/10.1128/AEM.70.8.4855-4863.2004

[8] Shi Y.H. (2012) Isolation and Identification of Pesticides-Degrading Bacterium Pseudomonas stutzeri YC-YH1 and Study of Degradation Mechanism.

[9] Holden, P.A. and Firestone, M.K. (1997) Soil Microorganisms in Soil Cleanup: How 
Can We Improve Our Understanding? Journal of Environmental Quality, 26, 32-40. https://doi.org/10.2134/jeq1997.00472425002600010006x

[10] Vidali, M. (2001) Bioremediation. An Overview. Pure \& Applied Chemistry, 73, 1163-1172. https://doi.org/10.1351/pac200173071163

[11] Chen, K., Liu, X.M., Li, R., Liu, Y., Hu, H., Li, S.P., et al. (2011) Isolation of a Buprofezin Co-Metabolizing Strain of Pseudomonas sp. DFS35-4 and Identification of the Buprofezin Transformation Pathway. Biodegradation, 22, 1135-1142. https://doi.org/10.1007/s10532-011-9469-x

[12] Yu, T. (2015) Biological Characteristics of Organophosphate Degrading Bacteria and Enzymology Properties Analysis of Organophosphate Degradation Enzyme.

[13] Aboamer, A. (2011) Biodegradation of Diazinon by Serratia marcescens DI101 and Its Use in Bioremediation of Contaminated Environment. Journal of Microbiology \& Biotechnology, 21, 71. https://doi.org/10.4014/jmb.1007.07024

[14] Sen, R. and Swaminathan, T. (2004) Response Surface Modeling and Optimization to Elucidate and Analyze The Effects of Inoculum Age and Size on Surfactin Production. Biochemical Engineering Journal, 21, 141-148.

https://doi.org/10.1016/j.bej.2004.06.006

[15] Gangadharan, D., Sivaramakrishnan, S., Nampoothiri, K.M., Sukumaran, R.K. and Pandey, A. (2008) Response Surface Methodology for the Optimization of Alpha Amylase Production by Bacillus Amyloliquefaciens. Bioresource Technology, 99, 4597-4602. https://doi.org/10.1016/j.biortech.2007.07.028

[16] Mahiudddin, M., Fakhruddin, A.N.M., Chowdhury, M.A.Z., Rahman, M.A. and Alam, M.K. (2014) Degradation of the Organophosphorus Insecticide Diazinon by Soil Bacterial Isolate. International Journal of Biotechnology, 2014, 12-23.

[17] Sikora, L.J., Kaufman, D. and Hornog, L.C. (1990) Enzyme Activity in Soils Showing Degradation of Organophosphosphate Insecticides. Biology and Fertility of Soils, 9, 14-18. https://doi.org/10.1007/BF00335855

[18] Racke, K.D. and Robbins, S.T. (1991) Factors Affecting the Degradation of 3,5,6-trichloro-2-pyridinol in Soil. ACS Symposium Series, 459, 93-107. https://doi.org/10.1021/bk-1991-0459.ch007

[19] Yang, L., Zhao, Y.H., Zhang, B.X. and Zhang, X. (2005) Isolation and Characterization of a Chlorpyrifos Degrading Bacteria and Its Bioremediation Application in the Soil. Acta Microbiologica Sinica, 45, 905-909.

[20] Zhang, D.Y., Tan, X.Q., Luo, X.W., Zhu, C.H., Luo, Y.H., Ming-Yuan, H.E., et al. (2005) Isolation of Photosynthetic Bacteria hp-1 with Degradation of Organic-Phosphorus Insecticides and Studies on Its Biodegradation Ability and Capacity of Increasing Growth. Life Science Research, 9, 247-253.

[21] Xu, G.M., Zheng, Y.Y., Wang, S.H., Zhang, J.S. and Yan, Y.C. (2008) Biodegradation of Chlorpyrifos and 3,5,6-trichloro-2-pyridinol by a Newly Isolated Paracoccus sp. Strain TRP. International Biodeterioration \& Biodegradation, 62, 51-56. https://doi.org/10.1016/j.ibiod.2007.12.001 